\title{
Developmental Research on "Life Skill” Cultivation in P.E. Curriculum System of Universities
}

\author{
Huang Changwu \\ Physical Education Institute of Hunan University of Technology, China \\ doctor2000@yeah.net
}

Keywords: Physical Education of Universities; Cultivation; Teen-agers; Life Skills

\begin{abstract}
The paper is aimed at conducting a developmental and practical research on "life skill" cultivation in P.E. curriculum system of universities. In the research, 302 freshmen (137 male students and 165 female students) from College of Education and College of Humanities at Hunan University of Science and Technology were randomly selected to be the research targets. All selected students were then divided randomly into the experimental group and the contrast group, with 153 students in the experimental group and 149 students in the contrast group. These students were arranged to go through physical education experiment designed for improving teen-agers' life skills. Document literature, mathematical statistics, Likert-type scales and other methods were put into use in the research to test students' knowledge and confidence in life skills for subsequent assessment. The experimental result has shown that, students in the experimental group were observably improved $(\mathrm{P}<0.05) 1$ in one aspect of both life skill test and confidence test.
\end{abstract}

\section{Introduction}

Along with the sustainable development of Chinese politics and economy, social competition and people's pace of life is greatly intensified. For this reason, teen-agers are exposed to pressures from study, employment, as well as from many other aspects. What's worse, they are facing intrinsic perplexities in their growth stage as well, lacking of necessary physiological and spiritual adjustment. These factors have lead to a series of harmful mental emotions and social behavioral issues. As for this, it is a crucial task in quality education for us to develop life skill education, so as to help teen-agers to cope with the ever-changing social environment. [1] World Health Organization defines life skill as the ability of a person to handle effectively all kinds of requirements and challenges in daily life, as well as the ability of an individual to keep a good mental state, and to take on an adaptive and positive behavior in the correlations with other people, the society and the environment. [2] Life skill is mainly comprised by ten types (five pairs) of abilities: self-cognition ability - empathy ability, effective communicating ability - interpersonal relationship ability, the ability of dealing with emotional problems - the ability of relieving pressures, the ability of creative thinking - the ability of critical thinking, decision-making ability - the ability of fixing problems. [3]

Sports means a lot to life and the derivation of sports is closely related with human beings' social life. Researches have proved that physical training can help to enhance university students' mental health. [4] What's more, teen-agers' life skills can also be obtained through physical education to some extent. [5] Therefore, the intrinsic characteristic in physical education contains huge potential of development, and is a teaching advantage for carry out "life skill" cultivation. Some researchers even proposed that the best way to promote a new skill acquisition is to combing physical education with life skill teaching. [6] However, there is no systematic report in researches on the P.E. curriculum system of China. Based on the fact, the paper conducted a developmental and practical research on "life skill" cultivation in P.E. curriculum system of universities, for the quotation and reference of physical educators in the same field. 


\section{Research Target and Method}

\section{I . Research Target}

In the research, 302 freshmen (137 male students and 165 female students) from College of Education and College of Humanities at Hunan University of Science and Technology were randomly selected to be the research targets. The six classes were divided into two groups, with three classes in each group. In the experimental group, there were 153 students (69 male students and 84 female students), with an average age of $17 \pm 1.57$ and male-to-female ratio of 69:84. In the contrast group, the amount of students is 149 ( 68 male students and 81 female students), with an average age of $17 \pm 1.64$ and male-to-female ratio of 68:81. During life skill education, students in the experimental group were intervened specially according to prior-arrangement. On the contrary, the physical education that students in the contrast group received was the traditional type. Both the two group had employed the same teaching materials, syllabus, and teaching hours. There were as well no obvious differences in gender, age and skill performance of students from the two groups (in both groups, $\mathrm{P}>0.05$ ). Thus, the two groups were comparable.

\section{Research Method}

Experiment Schedule, Teaching Hours and Teaching Arrangement. During the period between September, 2009 and December, 2009, as well as the period between March, 2010 and June, 2010, the aforementioned teaching experiment was conducted in two semesters. Traditional physical education classes were scheduled 34 teaching hours in each semester, while the teaching time for "life skill" teaching mode is 26 hours in each semester, equal to 34 teaching hours. All curriculums in the experimental group were practice courses. In the first ten lessons, students were taught with two basketball skills: dribbling and chest pass. Afterwards, in the rest seven lessons, students were trained with two volleyball skills: two-handed overhead pass and underhand service. In the training phase, both the experimental group and the contrast group shared the same teaching contents. The only difference was that, a life skill instruction of about 15 minutes was added into each lesson in the experimental group. On the contrary, the contrast group would make use of the same time length to do relaxation exercises.

Teaching Plans for Life Skill Cultivation. Brief introduction to life skill cultivation is shown in Table 1, which consists of three aspects: target setting, policies for problem solving and positive thinking. At the beginning of basketball and volleyball training, related sports tests would be employed to check all students (as is mentioned in the following). After that (the first four lessons were basketball tests, while the eleventh and the twelfth lesson were volleyball tests), the test results were used as a stimulation, for the purpose of teaching students with the definition of goal and the principle of setting feasible goals. Then, students were required to reset their goals for test. Moreover, they were instructed on how to achieve the goals through making personal action plan.

In the fifth, the sixth, the seventh, the fifteenth and the sixteenth lesson, students were taught with the three-step procedure in solving a problem. The first step was to figure out solutions as many as possible in allusion to the existing problems. The second step was to deduce the result of each solution. The third step was to select out the solution with the best predicted result, as well as to apply and evaluate it. Afterwards, improved basketball and volleyball competitions with new solutions were demonstrated to students, and students were required to choose a solution with the help of the three-step procedure. In the seventh and the fifteenth lesson, students would have to take into consideration all stumbling blocks, avoiding these blocks from impeding students to achieve their goals. They would also have to make use of the three-step procedure to clear the stumbling blocks.

Course configuration. Course configuration is to establish connection among the each teaching project and specific teaching contents in network courses, mainly including three aspects: teaching tips, teaching resources and frequently-asked questions.

In the eighth, the ninth, the thirteenth and the fourteenth lesson, students were instructed on the definition of positive thinking, how positive thinking affected their performance, as well as how to discover negative thinking in practices and to transform then into positive thinking. We also taught 
students the ways to encourage themselves, especially self-encouragement with instructive function, and the ability to use proper key orders to concentrate their mind upon the most crucial elements of each sports skill. As for basketball, students were taught to take advantage of key orders of "low" and "speed" in dribbling, as well as "finger" and "target" in chest pass. In volleyball training, the key order of "triangle" was taught to use in over-arm pass, as well as "opening arms" and "fist" in underhand service. In the courses of goal setting and positive thinking, students would practice with the method of self-test in most occasions. In problem-solving courses, students were divided into group for operation. An operation manual was provided for students in the experimental group. Each section in the manual corresponded with one lesson, in which, students were able to find contents of life skill that had been taught.

\section{Evaluation Method of Life Skill Education}

\section{I . Knowledge Test}

A test of revised edition was adopted, and the test was developed by Papacharisis (2004), based on the research of Hogan (2000). [7] The test consists of 15 multiple-choice questions, which evaluated the following points: how to set the goals ( 5 questions), how to make positive thinking (5 questions) and how to solve problems (5 questions). The questions might go like this: "In order to realize my dream, (a) I ought to dream more dreams; (b) I should transform the dream into feasible goals; (c) I just have to wait and see; (d) There is no need for me to do anything, for anything destined to happen will happen sooner or later."

\section{II . Confidence Test}

The tools used for measure students' confidence in goal setting, problem solving and positive thinking is a test with 21 questions, and is a revised edition of the test that created by Papacharisis. In the year of 2004, Papacharisis declared that this three-element structure showed satisfactory internal consistency and structural effectiveness, taking up $58.6 \%$ of the square deviation. In the research of this paper, we employed 6 questions to evaluate students' perception over their goal setting ability (such as, "I am pretty good at setting goals for myself"); 4 questions to evaluate their perception over individual ability of positive thinking ( such as, "I am pretty good at positive thinking"); 4 questions to evaluate individuals' perception on transforming negative thinking into positive thinking (such as, "I am able to discover my negative thinking, and I can transform it into positive thinking"); 7 questions to evaluate individuals' perception upon their ability in problem solving (such as, "I am pretty good at find the best solution for the issues I am faced with"). The evaluation was conducted with Likert-type scales - a grading system frequently applied in social sciences, i.e. from 1 (completely disagreed) to 7 (fully agreed). An exploratory element analysis with oblique rotations had generated four additional elements, taking up $59 \%$ of the square deviation. The four elements consisted of goal setting (4 questions), positive thinking (3 questions), negative thinking transformation (4 questions) and problem solving (4 questions) and the Cronbach alpha coefficients of the four elements were separately $0.78,0.82,0.74$ and 0.75 .

\section{Test Results}

\section{I . Knowledge Test}

Before intervention, there was no obvious difference in knowledge test result between the two groups (in both groups, $\mathrm{P}>0.05$ ). By contrast, after intervention, the performance of both groups was improved (in both groups, $\mathrm{P}<0.05$ ), and the improvement of the experimental group was more remarkable $(42.5 \%$ VS $15.1 \%)$. The comparative difference of the two groups had statistical significance. 


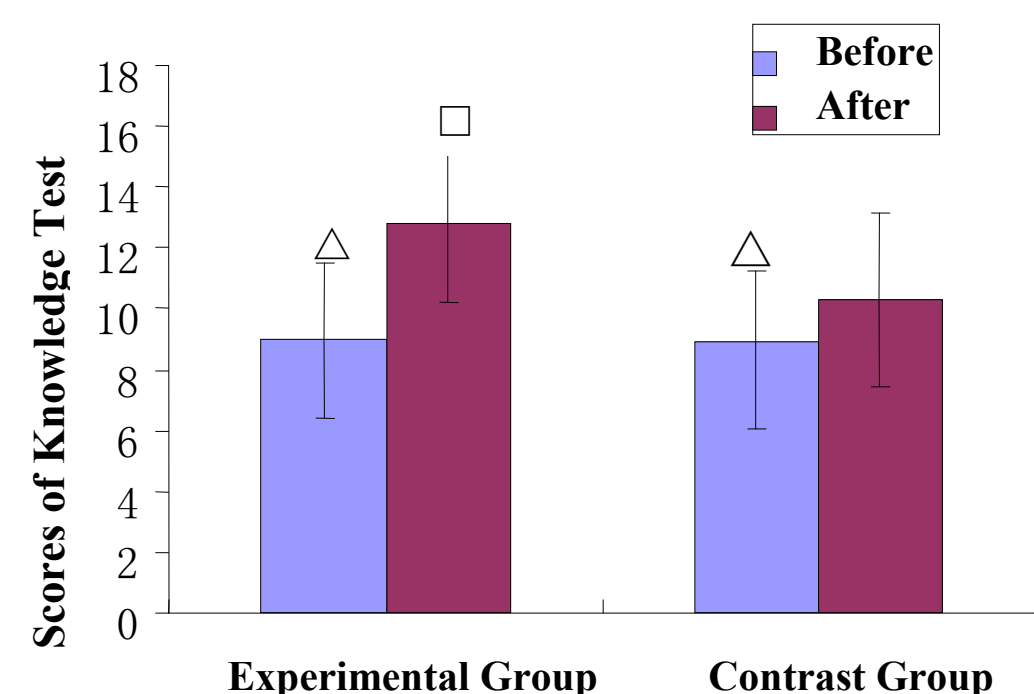

Figure 1 Knowledge Test of the Two Groups Before and After the Intervention

Remarks: " $\triangle$ " refers to the comparison with the same group after the intervention, and $\mathrm{P}<0.05$, while “ $\square$ " refers to the comparison with the contrast group after the intervention, and $\mathrm{P}<0.05$.

\section{II . Confidence Test}

Confidence test took four types of confidence as the dependent variables. Shown by a multivariate $\mathrm{T}$ test inspection and analysis, before intervention, there was no statistical significance in the difference of confidence degree between the two groups $(\mathrm{P}>0.05)$. However, after intervention, the overall confidence degree of the experimental group was superior to the contrast group, and the corresponding difference between the two groups took on a statistical significance $(\mathrm{P}<0.01)$. Further analysis also showed that, the improvement degree of the experimental group is obviously superior to the contrast group $(\mathrm{P}<0.01)$ only in the aspect of "negative thinking transformation". Although other three aspects, including "goal setting", "problem solving" and "positive thinking", were also improved to some extent, the difference made no statistical significance $(\mathrm{P}>0.05)$. Please refer to Table 1 for detailed comparison results.

Table 1 Comparison of Confidence Degree of the Two Groups before and after Intervention

\begin{tabular}{|c|c|c|c|c|c|}
\hline Confidence & Group & Pre-test & After-test & $\begin{array}{l}\text { P Value } \\
\text { Comparison } \\
\text { Within Group }\end{array}$ & $\begin{array}{l}\text { P Value } \\
\text { Comparison } \\
\text { Between Groups }\end{array}$ \\
\hline \multirow{2}{*}{ Goal Setting } & $\begin{array}{l}\begin{array}{l}\text { Contrast Group } \\
(\mathrm{n}=149)\end{array} \\
\end{array}$ & $5.11 \pm 1.02$ & $5.06 \pm 1.17$ & 0.693 & \multirow{2}{*}{0.085} \\
\hline & $\begin{array}{l}\text { Experimental Group } \\
(\mathrm{n}=153)\end{array}$ & $5.09 \pm 0.97$ & $5.27 \pm 0.98$ & 0.104 & \\
\hline \multirow{2}{*}{ Problem Solving } & $\begin{array}{l}\text { Contrast Group } \\
(\mathrm{n}=149)\end{array}$ & $5.07 \pm 1.01$ & $5.12 \pm 0.78$ & 0.602 & \multirow{2}{*}{0.137} \\
\hline & $\begin{array}{l}\text { Experimental Group } \\
(\mathrm{n}=153)\end{array}$ & $5.08 \pm 0.92$ & $5.25 \pm 0.74$ & 0.075 & \\
\hline \multirow{2}{*}{ Positive Thinking } & $\begin{array}{l}\text { Contrast Group } \\
(\mathrm{n}=149)\end{array}$ & $4.81 \pm 1.31$ & $4.83 \pm 1.44$ & 0.896 & \multirow{2}{*}{0.178} \\
\hline & $\begin{array}{l}\text { Experimental Group } \\
(\mathrm{n}=153)\end{array}$ & $4.86 \pm 1.17$ & $5.03 \pm 1.12$ & 0.198 & \\
\hline \multirow{2}{*}{$\begin{array}{l}\text { Negative } \\
\text { Thinking } \\
\text { Transformation }\end{array}$} & $\begin{array}{l}\begin{array}{l}\text { Contrast Group } \\
(\mathrm{n}=149)\end{array} \\
\end{array}$ & $4.83 \pm 1.17$ & $4.78 \pm 1.23$ & 0.710 & \multirow{2}{*}{0.007} \\
\hline & $\begin{array}{l}\text { Experimental Group } \\
(\mathrm{n}=153)\end{array}$ & $4.91 \pm 1.15$ & $5.25 \pm 1.01$ & $<0.001$ & \\
\hline
\end{tabular}




\section{Discussion}

The research designed 17 experimental lessons to inspect the effects of life skill cultivation in P.E. curriculum system. Corresponding teaching effect was rather inspiring. Compared with teenagers in the contrast group, students in the experimental group who had received life skill education were greatly improved in their life skills. Students' psychological and social ability were strengthened, and they learned to appraise, accept and acknowledge themselves objectively. In the process, their level of self-concept was also promoted. As a result, they would be able to overcome the influence of negative thinking, and to face confidently all difficulties. Meanwhile, they were also remarkably enhanced in social responsibility, target knowledge, social interests, as well as in other aspects.

Life skill cultivation aims to inspire students to form the psychological and social ability during the study process of observation, practice and enhancement. The research in this paper is conducted based on the teaching form of team action. Team actions with stronger interactivity will be able to provide students with unique opportunities to teach students with some specific life skills, such as the ability to solve problems, the ability of team cooperation, the ability to adjust to the social changes, etc.

The empirical teaching research that combines life skill cultivation with P.E. curriculums can be regarded as an effective teaching model for applying life skill cultivation upon children, teen-agers, and even adults, so as to improve their like skills. Thus, it is worthy of being used for reference and being popularized. Life skills can be instructed as a single course, or be integrated with other courses in a school. For example, it is possible for students to study music through setting a goal and then projecting a plan for achieving this goal. What's more, students can also concentrate their attention in the examination through certain words of self-motivation.

Generally speaking, life skill education is proposed in accordance with the development trend of the entire society, the requirements of educational reform, as well as the growing rules of the younger generations. Therefore, it is a core task for promoting the healthy development of teen-agers. Proper life skill education upon teen-agers can help to improve their psychological and social ability, which is beneficial for them to grow healthily. Moreover, it is also helpful in preventing teen-agers' psychological problems and psychological illness, as well as behaviors consequently aroused, such as smoking, excessive drinking, drug abuse, and even violence and suicide. Besides, life skill education can also facilitate teen-agers' socialization, helping them to cope with the ever-changing social environment positively and effectively. For the aforementioned reasons, to promote life skill cultivation in P.E. curriculums has profound significance and reference values.

\section{References}

[1] Peng Fei: Life Skill Education-An Aspect Should Never be Neglected by Quality Education. The 6th Academic Exchange of the Child and Adolescent Health Section of China Preventive Medical Association, Beijing, 2004, p. 443-446.

[2] Ma Yinghua, Wang Fengqing, Hu Peijin, et al: Study of Teaching Model and Evaluation on the Life-skills Education and Psychology Health Promotion. Chinese Journal of School Health. Vol. 11(2007), p. 961-965.

[3] Zhang Lei, Sun Xuemei: Effects of Physical Exercise on Physical Self-Esteem and General Self-Efficacy of College Students. Journal of Tianjin Institute of Physical Education, vol. 24(2009), p. 172-174.

[4] Thompson E A, Hom M, Herring J R, et a1: Enhancing outcomes in an indicated drug prevention program for high-risk youth. Joumal of Drag Education. Vol. 27(1997), p. 19-41.

[5] Newbegin I, Owens A: Self-esteem and anxiety in secondary school achievement. Journal of Social Behaviour and Personality, Vol. 3(1996), p. 521-530.

[6] Botvin, G J, Griffin, et a1: Preventingillicit drug use in adolescents: Long-term follow-up data from a randomized comtrol trail of a schoolpepulation. Addieitive Behavior. Vol. 5(2000), p. 769-774.

[7] Peltzer, K, Promtussananon S: Evaluation of soul city school and nlasS media life skills education among junior secondary school learners in south Africa. Social Behavior and Personality. Vol. 31(2003), pp. 825-835. 